\title{
Inside the different types of carbon black as nanomodifiers for screen-printed electrodes
}

\author{
Vincenzo Mazzaracchio a, ${ }^{\text {, }}$, Maria Rita Tomei ${ }^{\text {a, }}{ }^{\text {, Ilaria Cacciotti }}{ }^{\text {b }}$, Angelica Chiodoni ${ }^{c}$, \\ Chiara Novara ${ }^{\mathrm{d}}$, Micaela Castellino ${ }^{\mathrm{d}}$, Giorgio Scordo ${ }^{\mathrm{d}}$, Aziz Amine ${ }^{\mathrm{e}}$, Danila Moscone ${ }^{\mathrm{a}}$, \\ Fabiana Arduini a, * \\ a Department of Chemical Science and Technology, University or Rome “Tor Vergata", Via Della Ricerca Scientifica 1, 00133, Rome, Italy \\ ' Department of Engineering, University or Rome "Niccolò Cusano", Via Don Carlo Gnocchi, 3 00166, Rome, Italy \\ c Center for Sustainable Future Technologies - CSFT@POLITO, Istituto Italiano di Tecnologia, Via Livorno, 60 - 10144, Torino, Italy \\ ${ }^{\mathrm{d}}$ Department of Applied Science and Technology, Polytechnic of Turin, C.so Duca Degli Abruzzi 24, 10129, Turin, Italy \\ e Department of Process Engineering and Environment, Faculty of Sciences and Techniques, Hassan II University of Casablanca, Morocco
}

\section{A R T I C L E I N F O}

\section{Article history:}

Received 18 February 2019

Received in revised form 9 April 2019

Accepted 22 May 2019

Available online 1 June 2019

\section{Keywords:}

Modified screen-printed electrodes

Carbon-based nanomaterials

Morphological characterisation

Structural characterisation

\begin{abstract}
A B S T R A C T
The need to deliver high performant and miniaturised electrochemical sensors has boosted the use of carbon nanomaterials as smart modifiers of working electrode surface. Among the carbon nanomaterials, the common and cost-effective carbon black has recently attracted the attention from the scientific community for its outstanding features as electrode nanomodifier for analyte detection. Herein, we report the structural and morphological characterisation of several types of carbon blacks, namely HP 160, HS20, MTN 990, N115, N220, N375, N660, PL6, Super P, and XE2B, by means of Raman spectroscopy, transmission electron microscopy (TEM) and scanning electron microscopy (SEM) analyses. Furthermore, the electrochemical characterisation of screen-printed electrodes modified with these carbon blacks was carried out by cyclic voltammetry and electrochemical impedance spectroscopy with ferro/ferricyanide as redox probe, highlighting the advantage to use carbon black as nanomodifier in respect to the bare electrode. Among several tested carbon black types, the lowest peak-to-peak separation and resistance to electron transfer values were achieved using screen-printed electrodes modified with CB N115, N375, HP 160 and PL6. The electrodes modified with these types of CB were successively tested in cyclic voltammetry towards epinephrine, benzoquinone, ascorbic acid, cysteine, catechol, and caffeic acid, observing a remarkable improvement of electrochemical performances in respect to the bare electrode, even when the amperometric mode was used. The results obtained demonstrated that several types of CB can remarkably improve the electrochemical performances of the sensors in terms of the decrease of applied potential or peak-to-peak separation, the improvement of the peak intensity, and the decrease of the resistance of the electron transfer due to several key features, including nanodimensions, the onionlike carbon structure, and the high number of defect sites.
\end{abstract}

๑) 2019 Elsevier Ltd. All rights reserved.

\section{Introduction}

Recent advances of nanotechnology have boosted the use of nanomaterials as smart components in the design of electrochemical sensors thanks to their countless features, including high surface area, large number of defect sites, easiness of

\footnotetext{
* Corresponding author.

E-mail address: fabiana.arduini@uniroma2.it (F. Arduini).

1 these authors contributed equally.
}

functionalisation, and fast electron transfer. Among carbon-based materials, the discovery of carbon nanotubes in 1991 by Ijima [1] laid out one of the main pillar in nanomaterial field, demonstrating how the carbon materials at nanoscale largely affect several characteristics of electrochemical sensors such as sensitivity, selectivity, tailorability, and robustness.

In 2004, Konstantin S. Novoselov and Andre K. Geim highlighted the features of a thick monocrystalline graphitic film, namely graphene, obtained from pyrolytic graphite by an easy exfoliation technique [2]. This thick monocrystalline graphitic film turned out in one of most promising nanomaterial in several fields including 
the electrochemical sensor one [3-5]. As highlighted in our recent review focused on graphene-based screen-printed electrodes (SPEs), graphene could be seen as a kaleidoscope because it confers different features to the sensing tools, being used to tailor the electrochemical properties of printed electrodes as well as to act as a label and loading agent for biomolecules and inorganic nanomaterials [6]. With the aim of employing sustainable and costeffective nanomaterials, since 2010 we have started to use carbon black as nanomodifier for printed sensors, taking into account that few applications were reported in literature until 2010 for analyte detection in solution [7,8]. Carbon black (CB) is an amorphous carbon belonging to pure soot and can be produced by incomplete combustion of carbon e.g. pyrolysis of carbonaceous industrial material. The most relevant production method is the oil furnace process, involving the partial combustion of aromatic liquid hydrocarbons in a furnace, delivering fine black particles with diameters in the range of $\mathrm{nm}$, which form fused aggregates at $\mu \mathrm{m}$ level. After 2010, some works have demonstrated the fascinating properties of $\mathrm{CB}$ as nanomaterial to provide high performing electrochemical sensors. Our group reported the attractive electrochemical properties of CB N220 to be used both in the ink/paste as well as in modifying electrodes by drop-casting for the quantification of several analytes such as phenolic compounds, NADH, thiols, ascorbic acid [9-11]. Its interesting features as nanomodifier for working electrode surface have been successfully demonstrated when compared with the most famous multiwalled carbon nanotubes [12,13] or graphene $[13,14]$. The enhancement in terms of electron transfer, sensitivity to the detected analyte, resistance to fouling, and decrease of applied potential for analyte quantification has been observed by using different types of $C B$, such as N220, M1100 [12], 5358 R [14], VXC72R [15], with several electrodes i.e. glassy carbon, carbon paste and screen-printed electrodes [16-20], demonstrating the robustness of this nanomaterial. Furthermore, additional interesting features of this nanomaterial rely on its use without any further chemical treatment (avoiding the use of strong oxidant as in the case of carbon nanotubes), the cost-effectiveness (around $1 €$ for $1 \mathrm{Kg}$ ), and the capability to obtain a stable dispersion useful to modify the electrode by an easily scalable dropcasting method. Although the outstanding electroanalytical properties have been mentioned and demonstrated by several research groups for a wide range of analytes e.g. amino acids [21], organic acid and DNA [22], dopamine and catechol [23], there is still a lack in the understanding the key features for the electrochemical behaviour. To address this issue, herein we report an electrochemical study of several types of carbon black namely HP 160 , HS20, MTN 990, N115, N375, N660, PL6, Super P, and XE2B by testing several species i.e. epinephrine, benzoquinone, ascorbic acid, cysteine, catechol, and caffeic acid in cyclic voltammetry. Moreover, a morphological and structural study has been combined with, to investigate the possible correlation between the $\mathrm{CB}$ structure and electrochemical behaviour of CB-based printed electrodes.

\section{Experimental section}

\subsection{Materials}

Potassium ferrocyanide $\left(\mathrm{K}_{4} \mathrm{Fe}(\mathrm{CN})_{6}\right)$, potassium ferricyanide $\left(\mathrm{K}_{3} \mathrm{Fe}(\mathrm{CN})_{6}\right)$, hexaammineruthenium(III) chloride, sodium phosphate dibasic $\left(\mathrm{Na}_{2} \mathrm{HPO}_{4}\right)$, epinephrine, benzoquinone, ascorbic acid, cysteine, catechol, caffeic acid, and N,N-dimethylformamide were purchased from Sigma-Aldrich (St. Louise, USA). CB N220, N115, N375, and N660 were obtained from Cabot Corporation (Ravenna, Italy). HP 160 and HS20 were purchased by Orion Engineered Carbons (Kingwood, USA). MTN 990, PL6, Super P, and XE2B were kindly supplied by Prof. Franco Cataldo.

\subsection{Screen-printed electrode fabrication}

SPEs were produced using a 245 DEK (Weymouth, UK) screenprinting machine. Flexible polyester film (Autostat HT5), purchased from Autotype Italia (Milan, Italy), was used as substrate to print the electrodes. Graphite-based ink (Electrodag $423 \mathrm{SS}$ ) from Acheson (Milan, Italy) was used to print both the working and auxiliary electrodes, while silver/silver chloride ink (Electrodag 6038 SS) to print the pseudo-reference electrode, and Grey Dielectric Paste D2070423P5 from Gwent Electronic Materials (Pontypool, UK) for the insulating layer to define the working electrode surface area. The resultant diameter of the working electrode was $0.3 \mathrm{~cm}$ with a geometric area equal to $0.07 \mathrm{~cm}^{2}$.

\subsection{Procedure of $C B$ dispersion}

The powder of each CB kind was dispersed in a mixture of dimethylformamide/water in ratio $1: 1 \mathrm{v} / \mathrm{v}$ for a final concentration of $1 \mathrm{mg} / \mathrm{mL}$. In detail, $10 \mathrm{mg}$ of each CB were first dipped in $5 \mathrm{~mL}$ of dimethylformamide and then $5 \mathrm{~mL}$ of water were added. The dispersion was sonicated for $60 \mathrm{~min}$ at $59 \mathrm{kHz}$.

\subsection{Procedure for SPE modification}

SPEs were modified using drop-casting method by adding on the surface of working electrode $6 \mu \mathrm{L}$ of the dispersion via three successive steps of $2 \mu \mathrm{L}$. The modified SPEs were tested after the evaporation of the solvent used for the dispersion.

\subsection{Electrochemical study}

Cyclic voltammetry (CV), amperometry and Electrochemical Impedance Spectroscopy (EIS) were performed by using the portable potentiostat PalmSens ${ }^{4}$ (Palm Instrument, The Netherlands) connected to a laptop and controlled by PSTrace software. CV and EIS measurements were carried out using a solution of $5 \mathrm{mM}$ ferro/ferricyanide $(1: 1 \mathrm{v} / \mathrm{v})$ in $\mathrm{KCl} 0.1 \mathrm{M}$. In the case of EIS measurements, a frequency range between $1 \mathrm{~Hz}$ and $10 \mathrm{KHz}, 10$ frequencies per decade, at an open circuit potential, with a voltage amplitude of $0.01 \mathrm{~V}$, was used while data fitting was provided by ZView software (Scribner Associates Inc.). Cyclic voltammetry was also used as technique to test epinephrine, benzoquinone, ascorbic acid, cysteine, catechol, and caffeic acid at concentration of $2 \mathrm{mM}$ in phosphate buffer $0.05 \mathrm{M}+\mathrm{KCl} 0.1 \mathrm{M}, \mathrm{pH}$ 7.4.

\subsection{Microstructural characterisation}

Raman analyses were performed to investigate the structure and defectiveness of the $\mathrm{CB}$ samples. The Raman spectra were acquired by a Renishaw inVia Reflex Raman microscope (Renishaw plc, Wotton-under-Edge, UK) equipped with a $785 \mathrm{~nm}$ solid state laser source. The radiation was focused through a $20 \times$ objective and collected in backscattering configuration, using a laser power of $10 \mathrm{~mW}$ and an acquisition time of $50 \mathrm{~s}$. To further reduce the power density, a defocusing level of $70 \%$ was selected. Each CB sample was analysed at three different positions and the obtained spectra were fitted and deconvoluted according to the 5 curves method proposed by Sadezky et al. [24] by means of the Raman software WiRE 5.1. The $\mathrm{I}_{\mathrm{D}} / \mathrm{I}_{\mathrm{G}}$ ratio was calculated starting from the intensities of the $\mathrm{D}$ and $\mathrm{G}$ curves obtained by the deconvolution procedure.

X-ray photoelectron spectroscopy (XPS) studies were carried out with a PHI 5000 Versaprobe Scanning X-ray photoelectron spectrometer (monochromatic Al K-alpha X-ray source with 
$1486.6 \mathrm{eV}$ energy) in order to investigate surface chemical composition. A spot size of $100 \mu \mathrm{m}$ was used to collect the photoelectron signal for both the survey and the high-resolution (HR) spectra. All samples were analysed using a combined electron and argon ion gun neutralizer system to reduce the charging effect during the measurements. Spectra were analysed using Multipak 9.0 dedicated software. All core-level peak energies were referenced to $\mathrm{C} 1 \mathrm{~s}$ peak at $284.5 \mathrm{eV}$ and the background contribution in HR scans has been subtracted by means of a Shirley function [25].

The nanoparticles size and shape were investigated with transmission electron microscopy. The powders were dispersed in ethanol and a drop of dispersion was put on a standard holey carbon copper grid. The measurements were carried out with a FEI TECNAI F20ST operating at $200 \mathrm{KV}$.

The deposition and distribution of the used CB dispersion on the surface of the SPE working electrode were analysed at field emission scanning electron microscopy (FEG-SEM, Leo Supra 35, UK).

\section{Results and discussion}

\subsection{Structural and morphological characterisation}

TEM analyses were conducted on the different CBs with the aim to evaluate their morphological and structural properties. In Fig. 1 two magnifications for each type of $\mathrm{CB}$ are reported. All the samples exhibit an onion-like carbon structure [26,27]. In details, XE2B powder is composed of hollow polyhedral carbon onions with few (4-8) layers (Fig. $1 \mathrm{~L}$ ), observing that the layer distance fits that of graphene layers and particles size is in the $10-20 \mathrm{~nm}$ range. PL6 and Super P (Fig. $1 \mathrm{H}$ and $1 \mathrm{I}$ ) powders show the same structural characteristics: they consist of multi-layered carbon onion (10-30 layers), as the predominant component, with an amorphous core and the particle size in the range of $20-50 \mathrm{~nm}$. The not regular distance of the layers can be attributed to a reduced degree of graphitization [28]. Sample HP 160 (Fig. 1 A) presents of carbon onions with size in the range of 10-25 nm, composed of tenths of graphitic-like layers, with a very small inner amorphous core and with very irregular interplanar distances. Similar features can be found in samples N115 (Fig. 1 D), N220 (Fig. 1 E) and N375 (Fig. 1 F), and with carbon onions size in the range of $20-40 \mathrm{~nm}$. Samples HS20 (Fig. 1 B), MNT 990 (Fig. 1 C) and N660 (Fig. 1 G) show the biggest particle size, with almost round carbon onion in the $50 \mathrm{~nm}$ range for HS20 and N660, and very big round carbon onion in the range of 200-300 nm for MNT 990. They consist of by tenths of graphitic-like layers with irregular interplanar distances. Except for the sample XE2B, all the samples show a remarked content of defects given by the not complete graphitization of the carbon onions. The correlation of these observations with Raman spectroscopy is of paramount importance to confirm and to also establish the role of these defects in the different types of CB.

Indeed, in carbon-based electrodes, the catalytic activity and electron transfer principally happens at the surface defect sites [29], and Raman spectroscopy is an useful technique to evaluate the disorder and imperfection of the carbon materials e.g. basal plane defects. The Raman spectra of the CB samples were therefore collected and are reported in Fig. 2.

All the spectra are characterised by the presence of two main vibrational features around 1580 and $1350 \mathrm{~cm}^{-1}$. The first band corresponds to the $E_{2 g}$ mode of graphite ( $G$ mode), due to the inplane vibration of the carbon-carbon bonds of the graphitic layers, while the second one (D mode), assigned to the breathing of the 6-membered rings, only arises in the presence of defects which disrupt the symmetry of the $\mathrm{sp}^{2}$ systems [30,31]. Three additional disorder-induced bands are identified: the $\mathrm{D}^{\prime}$ band around $1615 \mathrm{~cm}^{-1}$, the D3 band around $1500 \mathrm{~cm}^{-1}$, associated to the
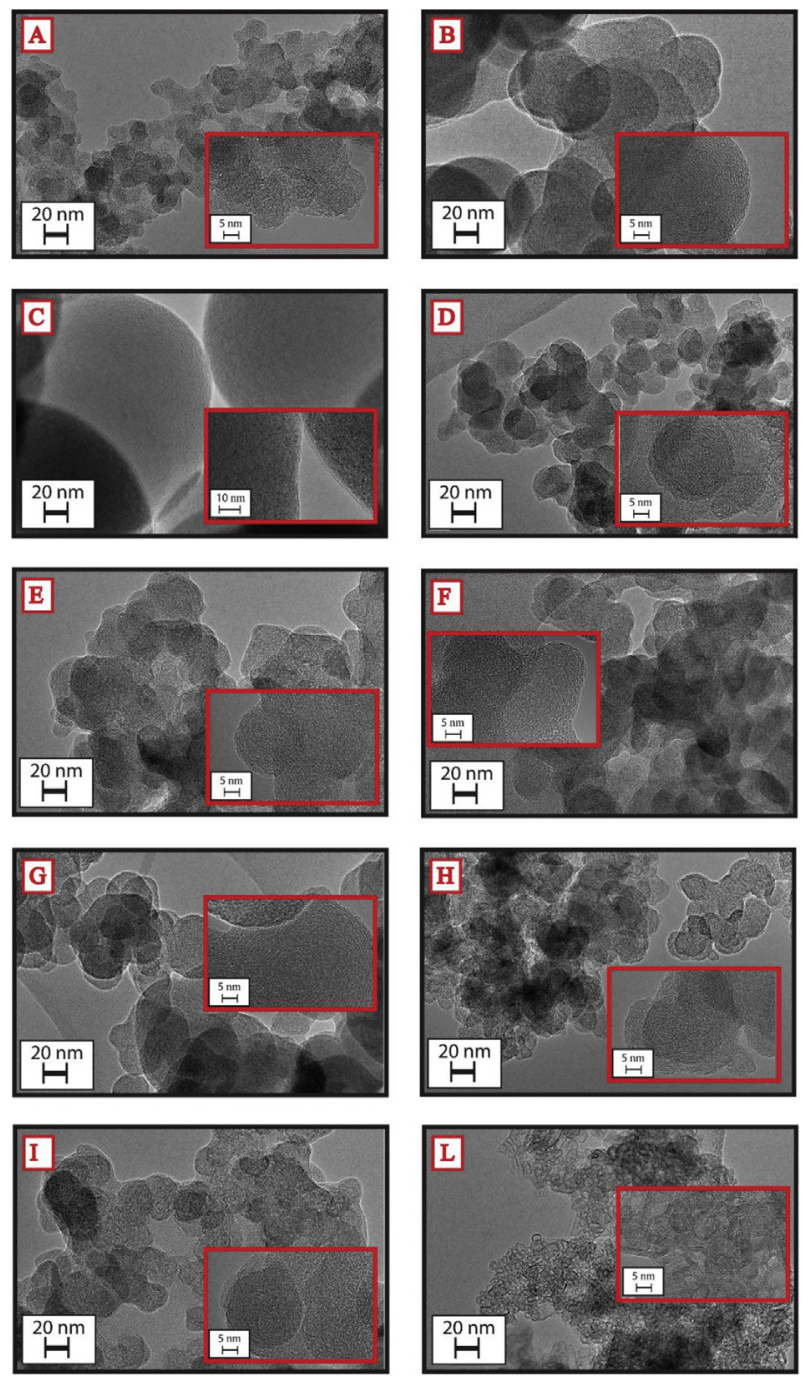

Fig. 1. TEM images of CB HP 160 (A), HS20 (B), MTN 990 (C), N115 (D), N220 (E), N375 (F) N660 (G), PL 6 (H), Super P (I), XE2B (L). (scale: 20 or $50 \mathrm{~nm}, 5 \mathrm{~nm}$ or $10 \mathrm{~nm}$ for the inset).

presence of amorphous carbon, and the usually weak D4 band at about $1200 \mathrm{~cm}^{-1}$. Their presence is pointed out by the deconvolution procedure of the first order Raman spectra of the CB samples according to the procedure optimized by Sadezky et al. [24]. Three broad and often unresolved bands appear instead in the high Raman shift range and correspond to the second order modes of the $\mathrm{D}\left(2 \mathrm{D}\right.$, at $\left.2675 \mathrm{~cm}^{-1}\right)$ and D' (2D', at $\left.3180 \mathrm{~cm}^{-1}\right)$ bands and to a combination mode of the $D$ and $G$ bands $\left(D+G\right.$, at $\left.2915 \mathrm{~cm}^{-1}\right)$ [32]. Despite the common vibrational pattern of the CB samples, some differences in the relative intensity ratios and band widths are noticed. In particular, the $\mathrm{I}_{\mathrm{D}} / \mathrm{I}_{\mathrm{G}}$ ratio is a useful parameter to evaluate the level of order/disorder in the graphitic carbon and its values calculated for the CB samples, are listed in Table 1. As a general trend, the nanometric $C B$ particles display higher $\mathrm{I}_{\mathrm{D}} / \mathrm{I}_{\mathrm{G}}$ ratios with respect to the bigger ones, probably because of the combination of a greater number of defects and an increased distortion of the graphitic-like domains at the surface of the small nanoparticles. Indeed, quite similar ratios, i.e. around 1.3 were detected for most of the samples, except for the N660 and MTN 990 powders, whose particle size is the largest, as evidenced from the related TEM images (Fig. $1 \mathrm{C}$ and $1 \mathrm{~F}$ ), resulting in the lowest $\mathrm{I}_{\mathrm{D}} / \mathrm{I}_{\mathrm{G}}$ ratios (around 1.2). Instead, the highest $\mathrm{I}_{\mathrm{D}} / \mathrm{I}_{\mathrm{G}}$ was measured for the 




Fig. 2. Normalized average Raman spectra of the $C B$ powders.

Table 1

Average $\mathrm{D}$ and $\mathrm{G}$ band positions and $\mathrm{I}_{\mathrm{D}} / \mathrm{I}_{\mathrm{G}}$ ratios obtained by the deconvolution of the first order Raman spectra of the $\mathrm{CB}$ powders.

\begin{tabular}{llll}
\hline Sample & $\mathrm{G}\left(\mathrm{cm}^{-1}\right)$ & $\mathrm{D}\left(\mathrm{cm}^{-1}\right)$ & $\mathrm{I}_{\mathrm{D}} / \mathrm{I}_{\mathrm{G}}$ \\
\hline HP 160 & $1577.0 \pm 0.1$ & $1346 \pm 2$ & $1.28 \pm 0.20$ \\
PL6 & $1575 \pm 5$ & $1342 \pm 3$ & $1.41 \pm 0.04$ \\
N220 & $1580.0 \pm 0.8$ & $1349 \pm 1$ & $1.28 \pm 0.06$ \\
N115 & $1578 \pm 2$ & $1348.0 \pm 0.5$ & $1.33 \pm 0.02$ \\
N375 & $1577.0 \pm 0.6$ & $1348 \pm 1$ & $1.27 \pm 0.01$ \\
XE2B & $1584 \pm 2$ & $1342 \pm 1$ & $1.57 \pm 0.06$ \\
N660 & $1577.0 \pm 0.2$ & $1355 \pm 3$ & $1.22 \pm 0.10$ \\
Super P & $1577.0 \pm 0.7$ & $1347.0 \pm 0.5$ & $1.41 \pm 0.03$ \\
HS20 & $1582.0 \pm 0.9$ & $1358.0 \pm 0.2$ & $1.32 \pm 0.02$ \\
MTN 990 & $1587 \pm 2$ & $1357.0 \pm 0.9$ & $1.19 \pm 0.08$ \\
\hline
\end{tabular}

XE2B, followed by the Super P and the PL6 samples. The increase of the relative intensity of the defect-induced $\mathrm{D}$ band for these particles is not only related to their small dimension, but also to their different structural features, as highlighted by a spectral profile characterised by narrow D and G bands. Indeed, it is well known that an increase of the $\mathrm{I}_{\mathrm{D}} / \mathrm{I}_{\mathrm{G}}$ ratio can be correlated to a decrease of the size of the graphitic-like domains [33]. The sharpness of the D and $G$ bands witnesses, however, a globally increased degree of crystalline order for such samples, consistently with a drop of the spectral intensity between the D and G bands. Such a decrease is due to a reduced contribution in this region of the D3 disorderinduced mode whose intensity was proposed to be indicative of the amorphous carbon content by previous studies on carbonaceous materials [32]. The greater graphitic fraction of these samples is also confirmed by an analogous narrowing of the band widths, observed in the second order region.

To establish the effect of the elemental composition of different CB samples, XPS analysis was carried out. Undeniably, XPS measurements seek to obtain information regarding the chemical state of each of the CB samples involved in this study, since electrochemical performances are deeply related with materials surface chemistry. From survey spectra (Fig. S1) we have obtained
Table 2

XPS relative atomic concentration (at.\%), obtained from HR spectra.

\begin{tabular}{lll}
\hline Sample & C1s & O1s \\
\hline HP 160 & 90.1 & 9.9 \\
PL6 & 97.3 & 2.7 \\
N220 & 98.3 & 1.7 \\
N115 & 98.4 & 1.6 \\
N375 & 96.7 & 3.3 \\
XE2B & 97.8 & 2.2 \\
N660 & 98.1 & 1.9 \\
Super P & 99.3 & 0.7 \\
HS20 & 97.0 & 3.0 \\
MTN 990 & 97.6 & 2.4 \\
\hline
\end{tabular}

information about elemental composition and relative atomic concentration of each present species (Table 2). The O concentration varies from 9.9 at.\% for sample HP160 to 0.7 for SUPER P sample: in between the average $\mathrm{O}$ concentration is almost 2 at.\%. Then, we focused our attention on $\mathrm{C} 1 \mathrm{~s}$ photoelectron peaks, to evaluate the chemical shifts due to the $\mathrm{C}-\mathrm{O}$ bonds. After a deconvolution procedure applied on all the C1s HR spectra (by using a pseudo-Voigt function for each peak), we obtained six components for all the samples apart from HP160, who needed an extra component $\left(\mathrm{C}-\mathrm{C} \mathrm{sp}{ }^{1}\right.$ at $\left.283.5 \mathrm{eV}\right)$ [34] to reproduce the experimental curve. The chemical shift found are: $\mathrm{C}-\mathrm{C} \mathrm{sp}{ }^{2}(284.5 \mathrm{eV})$, $\mathrm{C}-\mathrm{C} \mathrm{sp}{ }^{3}(285.2 \mathrm{eV}), \mathrm{C}-\mathrm{O}-\mathrm{C} / \mathrm{H}(286.0 \mathrm{eV}), \mathrm{O}-\mathrm{C}-\mathrm{O}(287.4 \mathrm{eV}),-\mathrm{O}-$ $\mathrm{C}=\mathrm{O}-(289.2 \mathrm{eV})$ and $\pi-\pi^{*}$ shake up satellite $(>291 \mathrm{eV})$ [35]. All the chemical shift percentages are reported in Table 3.

Finally, in order to investigate the deposition and the distribution of the used CB types on the surface of the working electrode, SEM analysis was carried out on all SPEs. From the comparison among the SEM micrographs reported in Fig. 3, it is evident that, in all cases, a continuous and uniform layer of CB particles was obtained, which completely covered the underneath randomly orientated micrometric graphite flakes, evidenced in the SEM micrograph of bare SPE (Fig. 3 A, B). Indeed, the bare SPE presented graphite flakes (Fig. $3 \mathrm{~A}$ ), characterised by numerous small particles consisting in the cross-linking agents present in the original ink (Fig. 3 B) [36]. Thus, these experimental evidences confirmed the obtainment of a good dispersion and the efficacy of the used dropcasting technique. However, in all cases it is possible to observe the presence of $\mathrm{CB}$ agglomerates, as expected: due to its very high specific surface area, $C B$ primary particles spontaneously tend to generate nanostructured aggregates which can form agglomerates, leading to distinct and characteristic porous structures based on nanometric spherical particles [37]. From the reported SEM micrographs, it is evident that the samples HP 160, N115, N220, N375, PL6, Super P and XE2B appear comparable, due to the similarity of the used $\mathrm{CB}$ powders, composed of nanometric particles (with an average diameter size of $20-40 \mathrm{~nm}$ ) which tend to aggregate due to their very high specific surface area, in very good agreement with TEM results (Fig. 1). On the other hand, the samples HS20, MTN 990 and N660 were characterised by bigger, more heterogeneous and more rounded particles, as evident from the higher magnifications micrographs (insets of Fig. 3 D, E and I, respectively), particularly in the case of MTN 990 modified SPE, being MTN 990 powder composed of heterogeneous particles with different diameter sizes (ranging between $100 \mathrm{~nm}$ and $300 \mathrm{~nm}$ ). In these latter cases, the bigger dimension of the used particles led to the formation of a less uniform layer, characterised by diffuse voids (Fig. 3 D, E and I, insets). Accordingly, the $\mathrm{CB}$ layers resulted more compact and uniform in the case of smaller CB particles modified SPEs (Fig. 3C, F, H, $\mathrm{L}, \mathrm{M}, \mathrm{N}$ ), as expected. 
Table 3

XPS C1s chemical shifts assignments, obtained from deconvolution procedures (not reported).

\begin{tabular}{|c|c|c|c|c|c|c|c|}
\hline \multirow[t]{2}{*}{ Sample } & \multicolumn{7}{|c|}{ C1s components } \\
\hline & $\begin{array}{l}283.5 \mathrm{eV} \\
\mathrm{C}-\mathrm{C} \mathrm{sp}{ }^{1}\end{array}$ & $\begin{array}{l}284.5 \mathrm{eV} \\
\mathrm{C}-\mathrm{C} \mathrm{sp^{2 }} \\
\end{array}$ & 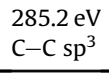 & $\begin{array}{l}286.0 \mathrm{eV} \\
\mathrm{C}-\mathrm{O}-\mathrm{C} / \mathrm{H}\end{array}$ & $\begin{array}{l}287.4 \mathrm{eV} \\
\mathrm{O}-\mathrm{C}-\mathrm{O}\end{array}$ & $\begin{array}{l}289.2 \mathrm{eV} \\
-\mathrm{O}-\mathrm{C}=\mathrm{O}-\end{array}$ & $\begin{array}{l}291.0 \mathrm{eV} \\
\pi-\pi^{*} \text { shake up }\end{array}$ \\
\hline HP 160 & $19.99 \%$ & $52.34 \%$ & $9.07 \%$ & $3.64 \%$ & $9.26 \%$ & $2.19 \%$ & $3.50 \%$ \\
\hline HS20 & - & $67.65 \%$ & $12.95 \%$ & $7.99 \%$ & $4.22 \%$ & $2.95 \%$ & $4.24 \%$ \\
\hline MTN 990 & - & $67.90 \%$ & $16.01 \%$ & $6.11 \%$ & $3.58 \%$ & $1.83 \%$ & $4.58 \%$ \\
\hline N115 & - & $63.73 \%$ & $12.47 \%$ & $8.74 \%$ & $4.64 \%$ & $3.99 \%$ & $6.43 \%$ \\
\hline N220 & - & $65.51 \%$ & $8.87 \%$ & $9.12 \%$ & $5.53 \%$ & $4.07 \%$ & $6.91 \%$ \\
\hline N375 & - & $62.59 \%$ & $14.49 \%$ & $8.80 \%$ & $5.55 \%$ & $2.94 \%$ & $5.63 \%$ \\
\hline N660 & - & $67.25 \%$ & $11.84 \%$ & $8.17 \%$ & $4.27 \%$ & $2.88 \%$ & $5.59 \%$ \\
\hline PL6 & - & $64.00 \%$ & $11.52 \%$ & $9.33 \%$ & $5.23 \%$ & $3.69 \%$ & $6.23 \%$ \\
\hline Super P & - & $67.97 \%$ & $13.71 \%$ & $5.78 \%$ & $4.41 \%$ & $2.71 \%$ & $6.41 \%$ \\
\hline XE2B & - & $59.36 \%$ & $19.23 \%$ & $5.44 \%$ & $5.14 \%$ & $3.54 \%$ & $7.30 \%$ \\
\hline
\end{tabular}
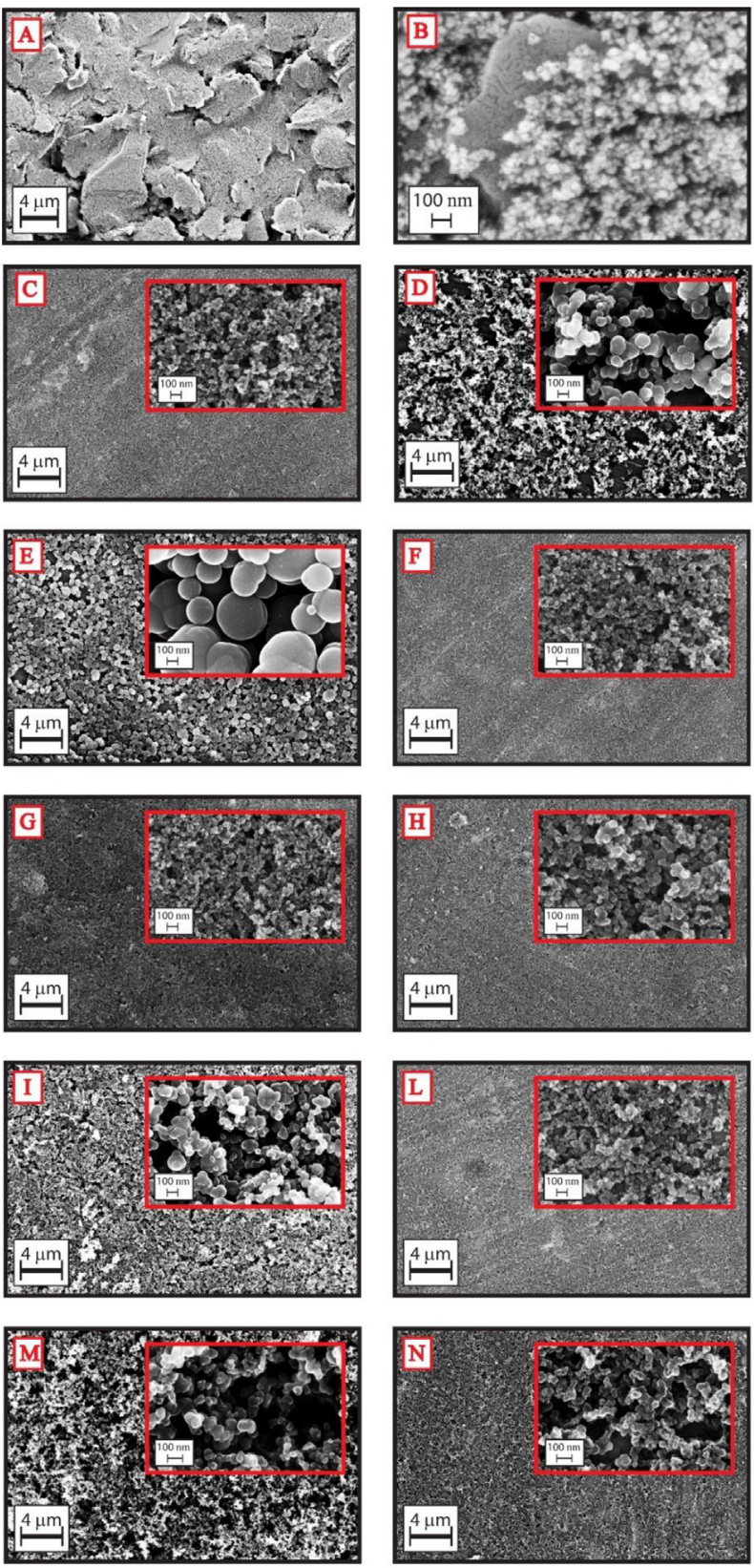

Fig. 3. SEM micrographs of the bare SPE (A-B) and of the SPEs modified with HP 160 (C), HS20 (D), MTN 990 (E), N115 (F), N220 (G), N375 (H), N660 (I), PL6 (L), Super P (M), XE2B (N) (insets: higher magnification micrographs).

\subsection{Electrochemical characterisation using ferro/ferricyanide as redox probe}

In order to evaluate the electrochemical performances of $\mathrm{CB}$ as nanomaterial for electrode fabrication, the most common approach relies on the modification of well-known characterised electrode materials by drop casting. To explore the response of CB-modified electrode surface in function of coverage effect, which can affect the electrochemical performances [7], the response of ferro/ferricyanide was evaluated after having modified the working electrode surface with $2,4,6$ and $8 \mu \mathrm{L}$ of different $\mathrm{CB}$ dispersions at concentration of $1 \mathrm{mg} / \mathrm{mL}$. As depicted by Fig. 4, generally at increasing of $\mathrm{CB}$ amount a decrease of peak to peak separation was observed, in combination with the increase of peak intensity, due to the higher amount of CB cast on the working electrode surface. Taking into account the electrochemical performances as well as the time of modified electrode preparation, $6 \mu \mathrm{L}$ (means $6 \mu \mathrm{g}$ of $\mathrm{CB}$ ) was selected as optimal volume of dispersion at $1 \mathrm{mg} / \mathrm{mL}$ to cast on the working electrode surface, in agreement with our previous work using only CB N220 [11]. After having selected the amount of CB, cyclic voltammetric measurements were carried out to obtain deeper information about the electrochemical properties of the different types of CB used as electrode modifier, except for CB N220 being previously largely characterised in our previous studies [9-11].

Fig. 5 shows the voltammograms obtained in ferro/ferricyanide $5 \mathrm{mM}+\mathrm{KCl} 0.1 \mathrm{mM}$, by using SPEs modified with the selected CBs. Different behaviours were observed depending on the $\mathrm{CB}$ used to modify SPEs by drop-casting method. SPE modified with MTN 990 gave the largest peak to peak separation (i.e. $470 \mathrm{mV}$ ) even when compared with bare SPE, and this behaviour is ascribed to its structure, which is not at the nanodimension level. A peak-to-peak separation comprised between 160 and $180 \mathrm{mV}$ was observed with SPEs modified with CB N660, N375, Super P. The smallest peak to peak separations were observed in the case of SPEs modified with $\mathrm{N} 115$ and HP 160 , being equal to $120 \pm 7$ and $129 \pm 6 \mathrm{mV}$, respectively.

To quantify the effect of $C B$ types on the electron transfer, the heterogeneous rate constant $\left(\mathrm{k}^{\circ}\right)$ for the ferro/ferricyanide redox probe was calculated based on Nicholsons theory [38], using $D_{O}=D_{R}=5.9 \times 10^{-5} \mathrm{~cm}^{2} / \mathrm{s}$ and an electrochemical transfer coefficient $\alpha=0.5$, taking into account that the $\mathrm{I}_{\mathrm{ap}} / \mathrm{I}_{\mathrm{cp}}$ value is very close to the unity for bare and CB modified SPEs [39]. The heterogeneous rate constants, reported in Table 4, highlighted the fastest electron transfer in the case of SPEs modified with N115 and HP 160, giving a value of $(6.3 \pm 0.6) \times 10^{-3}$ and $(5.4 \pm 0.9) \times 10^{-3} \mathrm{~cm} / \mathrm{s}$, respectively, which are comparable to the one obtained using CB N220 as modifier $\left(4.5 \times 10^{-3} \mathrm{~cm} / \mathrm{s}\right)$ using the same solvent for the dispersion and the same batch of $\mathrm{CB}$ [13]. In contrast, the lowest value of 

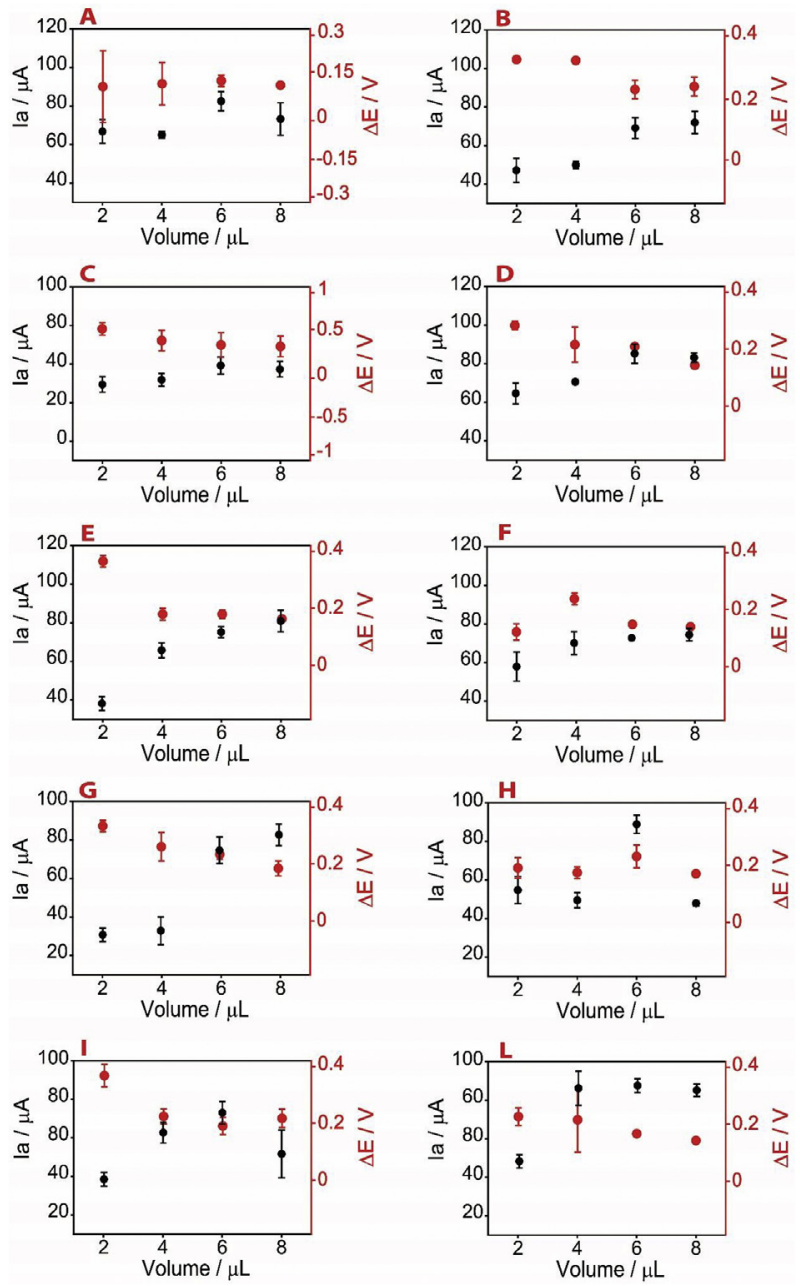

Fig. 4. Value for anodic peak current (black dots) and peak to peak separation (red dots) for SPE modified with $2 \mu \mathrm{L}, 4 \mu \mathrm{L}, 6 \mu \mathrm{L}$ and $8 \mu \mathrm{L}$ of CB dispersion HP 160 (A), HS20 (B), MTN 990 (C), N115 (D) N220 (E), N375 (F), N660 (G), PL6 (H), Super P (I), XE2B (L). (For interpretation of the references to colour in this figure legend, the reader is referred to the Web version of this article.)

heterogeneous rate constant was obtained using SPEs modified with $\operatorname{HS} 20(1.2 \pm 0.3) \times 10^{-3} \mathrm{~cm} / \mathrm{s}$.

Analysing the intensity of the anodic and cathodic peaks, the lowest intensities were observed using SPEs modified with CB Super P, N660, N375, HS20, MTN 990 with the anodic peak current equal to $73 \pm 1,75 \pm 6,73 \pm 3,73 \pm 1$, and $42 \pm 7 \mu \mathrm{A}$, respectively. In contrast, higher peak intensities were found using SPEs modified with HP 160, N115, PL6 and XE2B (i.e. $91 \pm 6,86 \pm 1,89 \pm 6$, and $88 \pm 2 \mu \mathrm{A})$.

The enhancement of the intensity of the anodic and cathodic peaks in the case of SPEs modified with these latter CBs is ascribed to the higher electroactive surface area calculated using RandlesSevcik equation with the diffusion coefficient equal to $\mathrm{D}=5.9 \times 10^{-5} \mathrm{~cm}^{2} / \mathrm{s}$ [40]. Indeed, these CB-SPEs were characterised by electroactive surface areas equal to $3.8 \pm 0.2,3.6 \pm 0.2$, $3.7 \pm 0.3$, and $3.7 \pm 0.2 \mathrm{~mm}^{2}$, respectively, higher values when compared with the other ones reported in Table 4 for the remaining CB-SPEs. In addition, as expected, the electroactive areas resulted higher than the one reported for the bare electrode, $1.6 \pm 0.2 \mathrm{~mm}^{2}$ calculated in our previous work [40].

Furthermore, the voltammetric peak intensity for each CB-SPE was evaluated as a function of the scan rate and plotted versus the square root of the scan rate $\left(\mathrm{v}^{0.5}\right)$. Fig. S2 showed linear

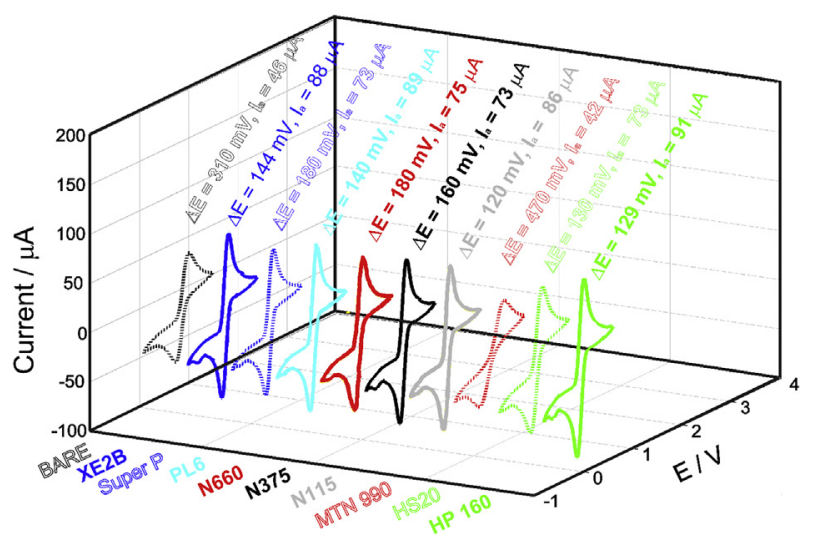

Fig. 5. Cyclic voltammetry measurements performed in $\left[\mathrm{Fe}(\mathrm{CN})_{6}\right]^{3-/ 4-} 5 \mathrm{mM}+\mathrm{KCl}$ $0.1 \mathrm{M}$, obtained with bare SPEs (dashed black line) and SPEs modified with HP 160 (green line), HS20 (dashed green line), MTN 990 (dashed red line), N115 (grey line), N375 (black line), N660 (red line), PL6 (cyan line), Super P (dashed blue line) and XE2B (blue line). (For interpretation of the references to colour in this figure legend, the reader is referred to the Web version of this article.)

behaviour for bare SPE and for each modified CB-SPE, indicating that the process is fully controlled by the diffusion of the electroactive species. The following slopes $\left(\mathrm{mA} /\left(\mathrm{mVs}^{-1}\right)^{0.5}\right)$ were obtained: $3.6 \pm 0.2\left(R^{2}=0.983\right), 13.6 \pm 0.4\left(R^{2}=0.992\right), 10.3 \pm 0.4$ $\left(\mathrm{R}^{2}=0.998\right), \quad 3.6 \pm 0.2 \quad\left(\mathrm{R}^{2}=0.937\right), \quad 12.7 \pm 0.3 \quad\left(\mathrm{R}^{2}=0.996\right)$, $14.9 \pm 0.3 \quad\left(R^{2}=0.993\right), \quad 11.0 \pm 0.4 \quad\left(R^{2}=0.990\right), \quad 12.8 \pm 0.4$ $\left(R^{2}=0.981\right), 9.0 \pm 0.4\left(R^{2}=0.987\right), 10.6 \pm 0.6\left(R^{2}=0.976\right)$, respectively for bare SPE, HP 160, HS20, MTN 990, N115, N375, N660, PL6, Super P, and XE2B. The highest slope was observed using HP 160, confirming its better electrochemical properties.

Additionally, we have analysed the variation of log Ip versus log $v$ using ferro/ferricyanide as redox probe, obtaining the following gradients $0.52 \pm 0.03, \quad 0.51 \pm 0.03, \quad 0.52 \pm 0.02, \quad 0.52 \pm 0.03$ $0.50 \pm 0.02, \quad 0.52 \pm 0.03, \quad 0.54 \pm 0.03, \quad 0.50 \pm 0.03, \quad 0.48 \pm 0.03$, respectively for HP 160, HS20, N115, N220, N375, N660, PL6, Super $\mathrm{P}$, and XE2B (Fig. S3). The values obtained, close to 0.5 , suggested no thin-layer effects, ensuring the absence of the redox probe entrapped within the network of the film. Therefore, a purely diffusional (semi-infinite) electrode response was observed. While in the case of bare SPE and SPE modified with MTN 990, a different gradient equal $0.37 \pm 0.02$ and $0.37 \pm 0.03$ was found, respectively, demonstrating a dissimilar behaviour in respect to nanomodified electrode.

To deeply investigate the electrochemistry of the different CBs, Electrochemical Impedance Spectroscopy (EIS) was used, obtaining information on the impedance changes of the electrode surface by varying the $\mathrm{CB}$ modifier (Fig. 6). Indeed, $\mathrm{R}_{\mathrm{ct}}$ value gives the difficulty of electron transfer of ferro/ferricyanide redox probe between the solution and the electrode, and its measurement can highlight the capability of $\mathrm{CB}$ to improve the electron transfer to the redox probe. Using this technique, the higher $\mathrm{R}_{\mathrm{ct}}$ values were observed in the case of SPEs modified with MTN 990, Super P and HS20 with $R_{c t}$ equal to $4 \pm 2 \mathrm{M} \Omega, 1.3 \pm 0.5 \mathrm{M} \Omega$, and $1.2 \pm 0.2 \mathrm{M} \Omega$, respectively, while the lowest $R_{\mathrm{ct}}$ using SPEs modified with HP 160, N115 and PL6 $(51 \pm 8,51 \pm 6$ and $55 \pm 7 \Omega$ ), confirming the behaviour of cyclic voltammetric experiments.

\subsection{Reproducibility and storage stability of $C B$ dispersion}

One of the main advantageous key feature of $C B$ is the facile preparation of a stable dispersion assisted by just one-step of sonication (60 $\min$ at $59 \mathrm{kHz}$ ) without any further chemical and 
Table 4

Electrochemical and structural features of several CB types.

\begin{tabular}{|c|c|c|c|c|c|c|}
\hline Carbon Black & $\mathrm{k}^{0}(\mathrm{~cm} / \mathrm{s})$ & $\begin{array}{l}\text { Surface Area } \\
(\mathrm{BET})(\mathrm{m} / \mathrm{g})\end{array}$ & $\begin{array}{l}\text { Electroactive } \\
\text { Area }\left(\mathrm{mm}^{2}\right)\end{array}$ & Particle diameter $(\mathrm{nm})$ & $\mathrm{I}_{\mathrm{D}} / \mathrm{I}_{\mathrm{G}}$ & Analytes \\
\hline N220 & $\begin{array}{l}1.59 \times 10^{-2}[10], 4.5 \times 10^{-3}[13] \\
1.4 \times 10^{-2}[40]^{\mathrm{b}}, 1.85 \times 10^{-2}[41] \\
3.6 \times 10^{-3}[42]^{\mathrm{c}}\end{array}$ & $\begin{array}{l}124[45,43], \\
120[10]\end{array}$ & $\begin{array}{l}3.2[40], 9.3[44], \\
23 \text { [41], } 24 \text { [42], } \\
3.1 \text { [this work] }\end{array}$ & $\begin{array}{l}17.95-32.5[10], 19-29[43]^{\mathrm{a}} \\
19-25[44], 19-29[45]^{\mathrm{a}},, 25[16]\end{array}$ & $\begin{array}{l}0.96[10], \\
0.97[13], \\
1.28 \text { [this work] }\end{array}$ & $\begin{array}{l}\text { CAT [43], NADH [9,10,13,42], BQ [10], EP [10], } \\
\mathrm{H}_{2} \mathrm{O}_{2} \text { [10,44,49], Heme protein [40], Hg [50], } \\
\text { BPA [51,52], As [53], AA [44], Cys [13], } \\
\text { Phosphate [54], Glucose [44],HQ [44], } \\
\text { Free Chlorine [55] }\end{array}$ \\
\hline VXC72R & $9.26 \times 10^{-2}[16]^{\mathrm{d}}, 9.77 \times 10^{-3}[48]^{\mathrm{e}}$ & & & $52[17], 20-25[56], 32.1[16]$ & $\begin{array}{l}2.64[16,17], 1.01[56], \\
0.99[58]\end{array}$ & $\begin{array}{l}\text { DA [16,17,58,59], APAP [16,17,47,59,60], } \\
\text { AA [17], UA [17], LEV [47], Mesotrione [48], } \\
\text { Estriol [56], AM [57], NI [57], EP [58], IP [60], } \\
\text { PP [60], CAF [60], CAT [61] }\end{array}$ \\
\hline N375 & $3 \times 10^{-3}$ [this work] & $\begin{array}{l}90[10], \\
105[62,63]\end{array}$ & $\begin{array}{l}14[63], 3.1 \pm 0.1 \\
\text { [this work] }\end{array}$ & $36[62,63]$ & 1.27 [this work] & $\begin{array}{l}\text { NADH [10], Sulfonamides [62], Nitrite [63], } \\
\text { BQ [63], HQ [63] }\end{array}$ \\
\hline N772 & & $30[10,62,63]$ & $8[63]$ & $124[62,63]$ & & $\begin{array}{l}\text { NADH, Sulfonamides [62], Nitrite [63], } \\
\text { BQ [63], HQ [63] }\end{array}$ \\
\hline N115 & $6.3 \times 10^{-3}$ [this work] & & $\begin{array}{l}19 \text { [62], } 3.6 \pm 0.2 \\
\text { [this work] }\end{array}$ & & 1.33 [this work] & \\
\hline $\begin{array}{l}\text { Printex XE } 2 \\
\text { M } 430\end{array}$ & $8.1 \times 10^{-3}[8]$ & 950 & & $\begin{array}{l}30[7] \\
25-37[20]\end{array}$ & & $\begin{array}{l}\text { DA [7], AA [7,8], } \mathrm{Pb}[7], \mathrm{Cd}[7], \mathrm{Cu}[8] \\
\text { FM [20]. APAP [20] Phenolic compound [64] }\end{array}$ \\
\hline ECP-600JD & & $1270[65]$ & & $34[65]$ & & Paraoxon [65] \\
\hline M 1100 & & & & $14[12]$ & & Nicotine [12] \\
\hline 5358R & $1.7 \times 10^{-3}[14]^{\mathrm{f}}$ & & & $29[14]$ & $0.91[14]$ & \\
\hline BP4750 & $5.74 \times 10^{-3}[16]^{\mathrm{d}}$ & & & $26[16]$ & $2.36[16]$ & DA [16], APAP [16] \\
\hline E2000 & $6.23 \times 10^{-4}[16]^{\mathrm{d}}$ & & & $27[16]$ & $3.65[16]$ & DA [16], APAP [16] \\
\hline Super P Li & & & $50.84[66]^{\mathrm{f}}$ & & & \\
\hline HP 160 & $5.4 \times 10^{-3}[$ this work] & & $3.8 \pm 0.2$ [this work] & & 1.28 [this work] & AA, EP, CYS, BQ CA, CAT [This work] \\
\hline HS20 & $1.2 \times 10^{-3}$ [this work] & & $3.0 \pm 0.2[$ this work] & & 1.32 [this work] & \\
\hline MTN 990 & & & $1.7 \pm 0.1$ [this work] & & 1.19 [this work] & \\
\hline N660 & $\overline{2.6} \times 10^{-3}$ [this work] & & $3.2 \pm 0.2[$ this work] & & 1.22 [this work] & \\
\hline PL6 & $4.8 \times 10^{-3}$ [this work] & & $3.7 \pm 0.3$ [this work] & & 1.41 [this work] & \\
\hline Super P & $2.2 \times 10^{-3}$ [this work] & & $3.1 \pm 0.1$ [this work] & & 1.41 [this work] & \\
\hline $\mathrm{XE} 2 \mathrm{~B}$ & $4.3 \times 10^{-3}$ [this work] & & $3.7 \pm 0.2$ [this work] & & 1.57 [this work] & \\
\hline
\end{tabular}

Given by the company.

${ }^{\mathrm{b}}$ Using $\mathrm{D}_{0}=\mathrm{D}_{\mathrm{R}}=5.9 \times 10^{-6} \mathrm{~cm}^{\mathrm{b}} / \mathrm{s}$.

${ }^{c}$ Using $D_{0}=D_{R}=7.6 \times 10^{-6} \mathrm{~cm}^{\mathrm{b}} / \mathrm{s}$

d Using ruteniumexaammine.

Calculated by impedance measurements.

${ }^{\mathrm{f}}$ Calculated by chronocoulometry. $\mathrm{AA}=\mathrm{Ascorbic}$ Acid, $\mathrm{AM}=$ Amoxicillin, $\mathrm{APAP}=$ acetaminophen, $\mathrm{BQ}=$ Benzoquinone, $\mathrm{BPA}=\mathrm{Bisphenol} \mathrm{A}, \mathrm{CA}=\mathrm{Caffeic}$ acid, $\mathrm{CAF}=\mathrm{Caffeine}, \mathrm{CAT}=\mathrm{Catechol}$, $\mathrm{CYS}=\mathrm{Cysteine}, \mathrm{DA}=\mathrm{Dopamine}$,

FA = Folic Acid, EP = Epinephrine, FM = Ferrocenemethanol, IP = Isoproterenol, LEV = Levoflaxacina, $\mathrm{NI}=$ Nimesulide, $\mathrm{PP}=$ Propranolol, TRP $=$ Tryptophan, TYR = Tyrosine. 


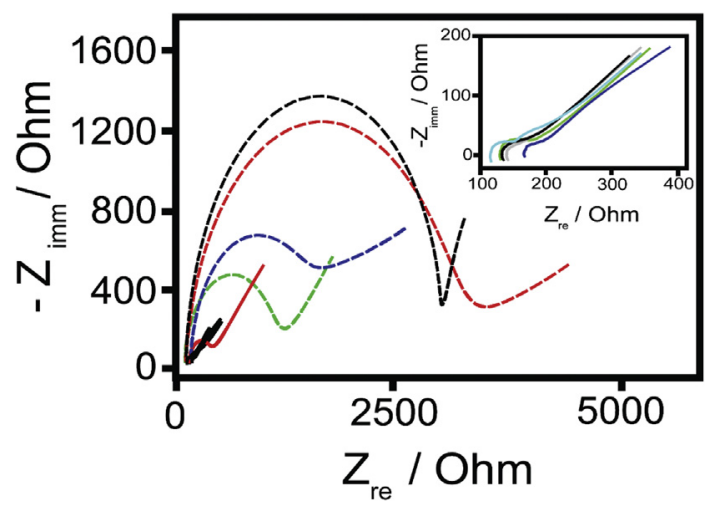

Fig. 6. Nyquist plot of EIS measurement obtained with bare SPEs (dashed black line) and modified SPEs with HS20 (dashed green line), MTN 990 (dashed red line), Super P (dashed blue line), and N660 (red line). Inset: Nyquist plot at high frequencies for EIS measurement obtained with SPEs modified with HP 160 (green line), N115 (grey line), N375 (black line), PL6 (cyan line), XE2B (blue line). Measurements performed in $\left[\mathrm{Fe}(\mathrm{CN})_{6}\right]^{3-/ 4-} 5 \mathrm{mM}+\mathrm{KCl} 0.1 \mathrm{M}$ at open circuit potential. (For interpretation of the references to colour in this figure legend, the reader is referred to the Web version of this article.)

physical treatment. The easy way to prepare a stable dispersion allows for a reproducible dispersion as well as reproducible CBmodified electrodes. The reproducibility of $\mathrm{CB}$ dispersion was investigated by modifying SPE with three different dispersions of each CB samples and by testing them with ferro/ferricyanide as redox probe. The results reported in Fig. S4 demonstrated similar electrochemical response towards the redox probe investigated within the experimental error, highlighting the reproducibility of the different $\mathrm{CBs}$ dispersion, even when diverse $\mathrm{CB}$ samples were used. The good reproducibility proved the robustness of the dispersion procedure preparation as well as the process of CBmodified electrode production, establishing a well-known route for CB-modified electrode fabrication.

Almost all CB samples gave a homogeneous dispersion by using just one-step of sonication, except XE2B and PL6, which required further sonication time. The homogeneity of the dispersions using different CB samples was evaluated in the same day of preparation and after 1 week, demonstrating good storage stability for almost all CB samples tested, except in the case of XE2B and PL6, for which a poor uniformity of the layer cast on the filter paper was observed (Fig. S5). The stability of CB dispersions has been also evaluated by drop-casting the dispersion with two-week as life-time, maintained at room temperature without any additional sonication step. In Fig. S4, the response of CB-modified SPEs prepared using a dispersion with $1 \mathrm{~h}$ (continuous black line) or two weeks as lifetime (dashed black line) sheds light a similar behaviour, demonstrating the good storage stability of almost all CB dispersions.

\subsection{Electrochemical behaviour of epinephrine, benzoquinone,} ascorbic acid, cysteine, catechol and caffeic acid

To get a further insight into CB types that gave the best performances using ferro/ferricyanide probe (i.e. HP 160, N115, N375 and PL6), the modified SPEs were challenged towards some interesting compounds for biological and environmental applications namely epinephrine, benzoquinone, ascorbic acid, cysteine, catechol and caffeic acid. Fig. 7 sheds light the improvement of all modified SPEs when compared with bare SPE (black dashed line), demonstrating the electrocatalytic properties of the different CBs tested.

For epinephrine, caffeic acid, benzoquinone, and catechol a decrease of peak to peak separation was observed together with an increase of the peak intensity. In the case of the epinephrine and
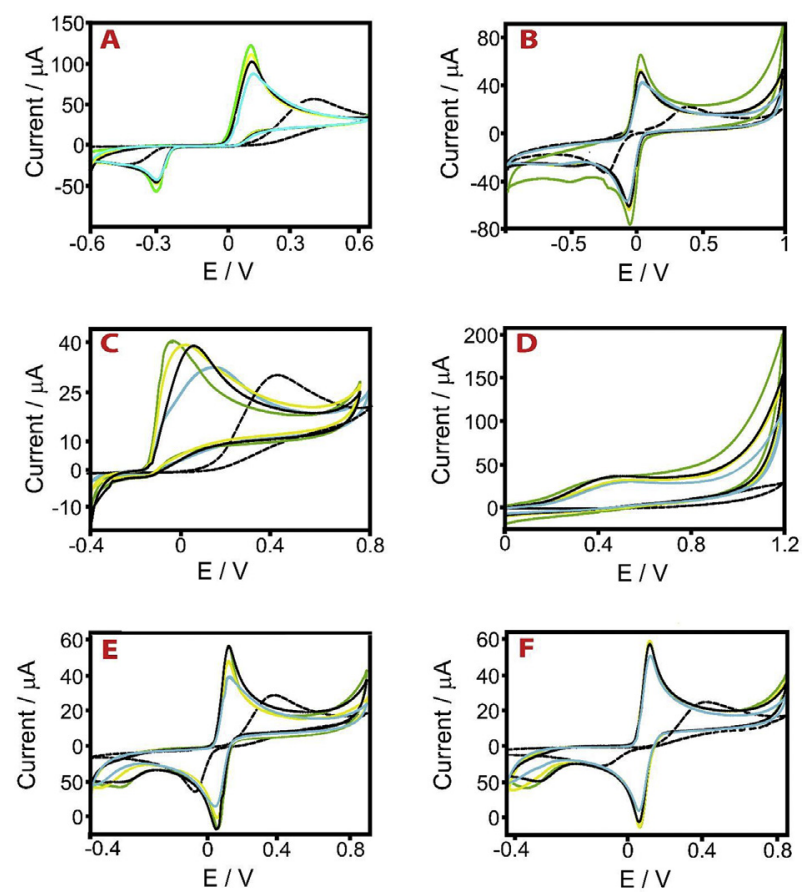

Fig. 7. Cyclic voltammograms obtained in phosphate buffer $0.05 \mathrm{M}+\mathrm{KCl} 0.1 \mathrm{M}$, pH 7.4 in presence of $2 \mathrm{mM}$ of epinephrine (A) benzoquinone (B), ascorbic acid (C), cysteine (D), catechol (E) and caffeic acid (F). All recorded at a scan rate of $50 \mathrm{mV} / \mathrm{s}$ using bare SPEs (dashed line) and SPEs modified with HP 160 (green line), N115 (yellow line), N375 (black line), and PL6 (cyan line). (For interpretation of the references to colour in this figure legend, the reader is referred to the Web version of this article.)

caffeic acid a smaller peak to peak separation combined with higher anodic and cathodic peak intensity was observed for SPEs modified with HP 160 and N115. For instance, the cyclic voltammetries of epinephrine using HP 160 and N115 gave a peak to peak separation equal to $422 \pm 6$ and $419 \pm 1 \mathrm{mV}$ and the anodic peak intensity equal to $111 \pm 4$ and $101 \pm 7 \mu \mathrm{A}$, respectively. In the case of benzoquinone and catechol the best electrochemical performances were observed using HP 160 and N375 as nanomodifier in terms of peak to peak separation (i.e. $109 \pm 1$ and $220 \pm 20$ in case of benzoquinone) and peak intensities (i.e. $36 \pm 2$ and $28 \pm 2 \mu \mathrm{A}$ in case of benzoquinone), respectively. For the irreversible redox reaction, as the case of ascorbic acid and cysteine, the presence of CB to modify working electrode surface largely decreased the applied potential allowing for the detection of the analyte at a lower applied potential as well as an improvement of sensitivity. In the case of ascorbic acid, the presence of the HP 160 and N115 gave the best resolution of the peaks and the lowest applied potential, while in the case of cysteine we observed a similar behaviour for all CBs tested. The achieved results demonstrated that $\mathrm{CB}$ positively affects the detection of the analytes decreasing the peak to peak separation in the case of (semi)reversible reaction or decreasing the applied potential, demonstrating the electrocatalytic properties of CB. In addition, in all cases we observed an increase of the sensitivity due to its high surface.

\subsection{Electroanalytical characterisation}

SPEs modified with the most performant CBs, namely HP 160 and N115, were tested in amperometric mode toward ascorbic acid and cysteine, analytes chosen for their importance in biological field as well as for their features in electrochemistry (e.g. fouling problem, high applied potential). In addition, to compare the behaviour with the well-known N220, the amperometric analyses 
were performed by using also SPEs modified with this latter CB. For the amperometric detection, applied potentials equal to $+50 \mathrm{mV}$ and $+400 \mathrm{mV}$ were chosen for ascorbic acid and cysteine detection, respectively, taking into account the previous cyclic voltammetries. As depicted in Fig. 8, for both ascorbic acid and cysteine detection, the presence of $\mathrm{CB}$ largely improves the sensitivity of the measurements in respect to the bare SPE (black line), overcoming the fouling problem, indeed successive additions of the analyte gave almost the same signal intensity. In the case of ascorbic acid detection (Fig. 8 A), higher sensitivity was obtained by using SPEs modified with $\mathrm{N} 220(0.021 \pm 0.001 \mu \mathrm{A} / \mu \mathrm{M})$ when compared to the ones obtained using SPEs modified with HP 160 and N115 (i.e. $0.016 \pm 0.002 \mu \mathrm{A} / \mu \mathrm{M}$ and $0.0196 \pm 0.0003 \mu \mathrm{A} / \mu \mathrm{M})$. Limit of detection (calculated as $\mathrm{S} / \mathrm{N}=3$ ) was found equal to $0.1 \mu \mathrm{M}, 0.4 \mu \mathrm{M}$ and $0.3 \mu \mathrm{M}$ for the SPEs modified respectively with N220, HP 160 and N115.

As for ascorbic acid detection, in the case of cysteine measurement, SPEs modified with CB N220 resulted in higher sensitivity, i.e. $(0.0217 \pm 0.0009) \mu \mathrm{A} / \mu \mathrm{M}$, compared with sensitivities obtained by using HP 160 and N115 modified SPEs, respectively equal to $(0.017 \pm 0.001) \mu \mathrm{A} / \mu \mathrm{M}$ and $(0.0161 \pm 0.0008) \mu \mathrm{A} / \mu \mathrm{M}$. The calculated LOD was $0.3 \mu \mathrm{M}, 1 \mu \mathrm{M}$ and $0.6 \mu \mathrm{M}$ for the SPEs modified respectively with N220, HP 160 and N115, confirming the better performances of N220.

\subsection{Discussion}

The morphological and structural characterisation combined with electrochemical studies with ferro/ferricyanide as redox probe, highlighted that the nanodimension of CB positively affects the electrochemical behaviour of the sensor when it is used as working electrode modifier. Undeniably, CB characterised by large particles gave only a smaller improvement of the electrochemical performances of electrodes: in the case of micromaterial MTN 990, modified electrode with CB MTN 990 gave similar performances in respect to the bare electrode, confirming the advantage of the nanodimension over the microdimension. Additionally, the case of HS20 and N660, with almost round carbon onion in the $50 \mathrm{~nm}$ range, a higher peak to peak separation and resistance to electron transfer $\left(R_{C T}\right)$ with lower peak intensity were observed, in respect to electrodes modified with CBs characterised by smaller nanoparticles. The results achieved demonstrated that the structure affects the electrochemical response: among the different $\mathrm{CB}$ samples, the ones with carbon onions size in the range of $10-25 \mathrm{~nm}$, composed of tenths of graphitic-like layers with a very small inner amorphous core and very irregular interplanar distances, namely HP 160, N220 and N375, provided the best electrochemical performances. As reported in literature [29], the defect
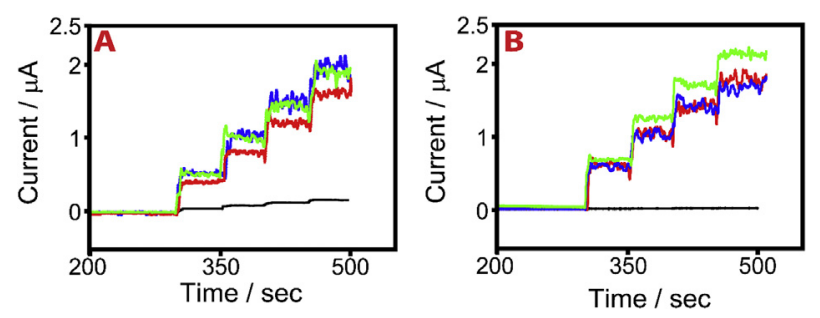

Fig. 8. Amperograms obtained in phosphate buffer $0.05 \mathrm{M}+\mathrm{KCl} 0.1 \mathrm{M}, \mathrm{pH} 7.4$, after successive addiction $(25 \mu \mathrm{M})$ of ascorbic acid (A) and cysteine (B), for bare SPE (black line) and modified with N220 (green line), N115 (blue line) and HP 160 (red line). Applied potentials equal to $+50 \mathrm{mV}$ and $+400 \mathrm{mV}$ to detect ascorbic acid and cysteine, respectively. (For interpretation of the references to colour in this figure legend, the reader is referred to the Web version of this article.) sites play a crucial role in electrocatalysis. CB samples are characterised by high number of defect sites with $\mathrm{I}_{\mathrm{D}} / \mathrm{I}_{\mathrm{G}}$ equal to 1.19 or higher, but the defect sites are not the only key features: XE2B has the highest $\mathrm{I}_{\mathrm{D}} / \mathrm{I}_{\mathrm{G}}$ with smaller particles size in the $10-20 \mathrm{~nm}$ range, with hollow polyhedral carbon onions with few (4-8) layers, but it is not the most performant $\mathrm{CB}$ among the $\mathrm{CB}$ tested. Another relevant issue regards the presence of surface functional groups e.g. $\mathrm{C}=\mathrm{O}, \mathrm{O}=\mathrm{C}-\mathrm{O}$, which highly affect the electrochemical response as demonstrated using inner-sphere probe i.e. ferro/ferricyanide. Otherwise, using no-sensitive surface electrochemical redox system i.e. hexaammineruthenium(III) chloride (outsphere probe) [67], the peak to peak separation is similar among the several CB types, having similar electronic structure. However, the higher peak to peak separation was observed in case of MTN 990, which has microstructure, while low values were observed with $\mathrm{CB}$ having smaller diameter of the nanoparticles (e.g. CB N115, HP 160, N220) (Table S1). Additionally, XPS analysis gave information related to the effect of C/O group on the electrochemical behaviour. HP 160, which is one the most promising $\mathrm{CB}$, is characterised by the higher content in $\mathrm{O}$ atoms (9.9 at.\%), while in the remnant samples the average $\mathrm{O}$ content is around 2.2 at.\%. Moreover it is the only one which possesses a chemical shift in the $\mathrm{C} 1 \mathrm{~s}$ photoelectron peak, due to $\mathrm{sp}^{1}$ hybridization (19.99\%), together with $\mathrm{sp}^{2}$ (52.34\%) and $\mathrm{sp}^{3}(9.07 \%)$, which are also present in the other samples. The more intense $\mathrm{C}-\mathrm{O}$ bond is the one due to $\mathrm{O}-\mathrm{C}-\mathrm{O}$ chemical shift at $1287.4 \mathrm{eV}$ (9.26\%), while an average value for the other samples is 4.7\%. Among the $\mathrm{C} / \mathrm{O}$ groups, the $\mathrm{CB}$ with higher content of $-\mathrm{O}-\mathrm{C}=$ O (i.e. N115 3.99\% and N220 4.07\%) is characterised by better electrochemical performances, demonstrating that $\mathrm{O}$ content and, in detail the $-\mathrm{O}-\mathrm{C}=\mathrm{O}$ amount, can give an improvement because of particular electrochemical electrocatalytic interaction with these specific surface oxygenated groups/species [16].

\section{Conclusions}

Herein, we reported a comparison among SPEs modified with several types of $\mathrm{CB}$ to investigate the influence of the morphological and structural characteristics of the investigated $\mathrm{CBs}$ on the electrochemical behaviour. The nanodimension of $C B$ allows for the development of highly sensitive sensor when compared with the bare one, with the advantage to be a cost-effective nanomaterial, to do not require any treatment before the use, and to easily furnish a stable dispersion needed for a reproducible and easy scalable dropcasting procedure. Several CBs were identified as the best candidates for the modification of the electrode surface such as HP 160 , N115, N220, N375 and PL6, demonstrating low peak to peak separation in the case of (semi)reversible species and low applied potential in the case of irreversible compounds, always associated to an increase of sensitivity. Because the well-established electrochemical properties combined with advantageous features reported above, several CBs deserve to be used as nanomodifier of electrochemical sensors. The reasons for these outstanding electrochemical properties are ascribed to nanodimensions onion-like carbon structure (carbon onions size in the range of $10-25 \mathrm{~nm}$ ), high number of defect sites $\left(\mathrm{I}_{\mathrm{D}} / \mathrm{I}_{\mathrm{G}}\right.$ ratios equal to 1.3 or higher), higher content in $\mathrm{O}$ atoms (especially $-\mathrm{O}-\mathrm{C}=\mathrm{O}$ groups). However, these characteristics are not the only ones able to furnish the high performant electrochemical behaviour of CB-modified electrodes, opening further questions about still undiscovered reasons.

\section{Acknowledgement}

This work was supported by NanoSWS project ERANETMED272-328 - RQ3-2016. 
Appendix A. Supplementary data

Supplementary data to this article can be found online at https://doi.org/10.1016/j.electacta.2019.05.117.

\section{References}

[1] S. Iijima, Synthesis of carbon nanotubes, Nature 354 (1991) 56-58.

[2] K.S. Novoselov, A.K. Geim, S.V. Morozov, D. Jiang, Y. Zhang, S.A. Dubonos, I.V. Grigorieva, A.A. Firsov, Electric field effect in atomically thin carbon films, Science 306 (2004) 666-669.

[3] M. Pumera, Graphene-based nanomaterials and their electrochemistry, Chem. Soc. Rev. 39 (2010) 4146-4157.

[4] D.A. Brownson, C.E. Banks, Graphene electrochemistry: an overview of potential applications, Analyst 135 (2010) 2768-2778.

[5] D.A. Brownson, G.C. Smith, C.E. Banks, Graphene oxide electrochemistry: the electrochemistry of graphene oxide modified electrodes reveals coverage dependent beneficial electrocatalysis, Royal Soc. Open Sci. 4 (2017) 171128.

[6] S. Cinti, F. Arduini, Graphene-based screen-printed electrochemical (bio) sensors and their applications: efforts and criticisms, Biosens. Bioelectron. 89 (2017) 107-122.

[7] S.B. Hočevar, B. Ogorevc, Preparation and characterization of carbon paste micro-electrode based on carbon nano-particles, Talanta 74 (2007) 405-411.

[8] I.G. Svegl, M. Bele, B. Ogorevc, Carbon black nanoparticles film electrode prepared by using substrate-induced deposition approach, Anal. Chim. Acta 628 (2008) 173-180.

[9] D. Talarico, F. Arduini, A. Constantino, M. Del Carlo, D. Compagnone, D. Moscone, G. Palleschi, Carbon black as successful screen-printed electrode modifier for phenolic compound detection, Electrochem. Commun. 60 (2015) $78-82$.

[10] F. Arduini, A. Amine, C. Majorani, F. Di Giorgio, D. De Felicis, F. Cataldo, D. Moscone, G. Palleschi, High performance electrochemical sensor based on modified screen-printed electrodes with cost-effective dispersion of nanostructured carbon black, Electrochem. Commun. 12 (2010) 346-350.

[11] F. Arduini, F. Di Nardo, A. Amine, L. Micheli, G. Palleschi, D. Moscone, Carbon black-modified screen-printed electrodes as electroanalytical tools, Electroanalysis 24 (2012) 743-751.

[12] T.W. Lo, L. Aldous, R.G. Compton, The use of nano-carbon as an alternative to multi-walled carbon nanotubes in modified electrodes for adsorptive stripping voltammetry, Sensor. Actuator. B. 162 (2012) 361-368.

[13] S. Cinti, F. Arduini, M. Carbone, L. Sansone, I. Cacciotti, D. Moscone, G. Palleschi, Screen-printed electrodes modified with carbon nanomaterials: a comparison among carbon black, carbon nanotubes and graphene, Electroanalysis 27 (2015) 2230-2238.

[14] C.H.A. Wong, A. Ambrosi, M. Pumera, Thermally reduced graphenes exhibiting a close relationship to amorphous carbon, Nanoscale 4 (2012) 4972-4977.

[15] P.B. Deroco, I.G. Melo, L.S. R Silva, K.I. B Eguiluz, G.R. Salazar-Banda, O. Fatibello-Filho, Carbon black supported Au-Pd core-shell nanoparticles within a dihexadecylphosphate film for the development of hydrazine electrochemical sensor, Sensor. Actuator. B Chem. 256 (2018) 535-542.

[16] F.C. Vicentini, A.E. Ravanini, L.C. Figueiredo-Filho, J. Iniesta, C.E. Banks, O. Fatibello-Filho, Imparting improvements in electrochemical sensors: evaluation of different carbon blacks that give rise to significant improvement in the performance of electroanalytical sensing platforms, Electrochim. Acta 157 (2015) 125-133.

[17] F.C. Vicentini, P.A. Raymundo-Pereira, B.C. Janegitz, S.A. Machado, O. FatibelloFilho, Nanostructured carbon black for simultaneous sensing in biological fluids, Sensor. Actuator. B Chem. 227 (2016) 610-618.

[18] D. Rojas, F. Della Pelle, M. Del Carlo, M. d'Angelo, R. Dominguez-Benot, A. Cimini, A. Escarpa, D. Compagnone, Electrodeposited Prussian Blue on carbon black modified disposable electrodes for direct enzyme-free $\mathrm{H}_{2} \mathrm{O}_{2}$ sensing ina Parkinson's disease in vitro model, Sensor. Actuator. B Chem. 275 (2018) 402-408.

[19] A.M. Santos, A. Wong, F.H. Cincotto, F.C. Moraes, O. Fatibello-Filho, Squarewave adsorptive anodic stripping voltammetric determination of norfloxacin using a glassy carbon electrode modified with carbon black and CdTe quantum dots in a chitosan film, Microchim. Acta 186 (2019) 148.

[20] D. Lowinsohn, P. Gan, K. Tschulik, J.S. Foord, R.G. Compton, Nanocarbon paste electrodes, Electroanalysis 25 (2013) 2435-2444.

[21] R.C. Carvalho, A. Mandil, K.P. Prathish, A. Amine, C. Brett, Carbon nanotube, carbon black and copper nanoparticle modified screen printed electrodes for amino acid determination, Electroanalysis 25 (2013) 903-913.

[22] V. Smolko, D. Shurpik, V. Evtugyn, I. Stoikov, G., EvtugynOrganic acid and DNA sensing with electrochemical sensor based on carbon black and pillar [5] arene, Electroanalysis 28 (2016) 1391-1400.

[23] F. Della Pelle, L. Vázquez, M. Del Carlo, M. Sergi, D. Compagnone, A. Escarpa, Press-printed conductive carbon black nanoparticle films for molecular detection at the microscale, Chem. A Euro. J. 22 (2016) 12761-12766.

[24] A. Sadezky, H. Muckenhuber, H. Grothe, R. Niessner, U. Poschl, Raman microspectroscopy of soot and related carbonaceous materials: spectral analysis and structural information, Carbon 43 (2005) 1731-1742.

[25] D. A. Shirley, High-resolution X-ray photoemission spectrum of the valence bands of gold, Phys. Rev. B 5 (1072) 4709-4714.
[26] G. Moussa, C.M. Ghimbeu, P.L. Taberna, P. Simon, C. Vix-Guterl, Relationship between the carbon nano-onions (CNOs) surface chemistry/defects and their capacitance in aqueous and organic electrolytes, Carbon 105 (2016) 628-637.

[27] Y. Lin, X. Sun, D.S. Xu, G. Centi, S. Perathoner, Catalysis by hybrid $\mathrm{sp}^{2} / \mathrm{sp}^{3}$ nanodiamonds and their role in the design of advanced nanocarbon material, Chem. Soc. Rev. 47 (2018) 8438-8473.

[28] O. Mykhailiv, H. Zubyk, M.E. Plonska-Brzezinska, Carbon nano-onions: unique carbon nanostructures with fascinating properties and their potential applications, Inorg. Chim. Acta 468 (2017) 49-66.

[29] C.E. Banks, J. Trevor, J. Davies, G.G. Wildgoose, R.G. Compton, Electrocatalysis at graphite and carbon nanotube modified electrodes: edge-plane sites and tube ends are the reactive sites, Chem. Commun. 7 (2005) 829-841.

[30] Coccato, J. Jehlicka, L. Moens, P. Vandenabeele, Raman spectroscopy for the investigation of carbon-based black pigments, J. Raman Spectrosc. 46 (2015) 1003-1015.

[31] A.C. Ferrari, D.M. Basko, Raman spectroscopy as a versatile tool for studying the properties of graphene, Nat. Nanotechnol. 8 (2013) 235-246.

[32] H.J. Seong, A.L. Boehman, Evaluation of Raman parameters using visible Raman microscopy for soot oxidative reactivity, Energy Fuels 27 (2013) $1613-1624$.

[33] L. Bokobza, J. L Bruneel, M. Couzi, Raman spectra of carbon-based materials (from graphite to carbon black) and of some silicone composites, Chimia 1 (2015) 77-94.

[34] M. Rybachuk, J.M. Bell, Electronic states of trans-polyacetylene, poly (p-phenylene vinylene) and sp-hybridised carbon species in amorphous hydrogenated carbon probed by resonant Raman scattering, Carbon 47 (2009) 2481-2490.

[35] F. Savazzi, F. Risplendi, G. Mallia, N. M., Harrison, G. Cicero, Unravelling some of the structure-property relationships in graphene oxide at low degree of oxidation, J. Phys. Chem. Lett. 9 (2018) 1746-1749.

[36] S. Cinti, D. Neagu, M. Carbone, I. Cacciotti, D. Moscone, F. Arduini, Nove carbon black-cobalt phthalocyanine nanocomposite as sensing platform to detect organophosphorus pollutants at screen-printed electrode, Electrochim. Acta 188 (2016) 574-581.

[37] Z.H. Li, J. Zhang, S.J., Effects of carbon blacks with various structures on vulcanization and reinforcement of filled ethylene-propylene-diene rubber, Express Polym. Lett. 2 (2008) 695-704.

[38] R.S. Nicholson, Theory and application of cyclic voltammetry for measurement of electrode reaction kinetics, Anal. Chem. 37 (1965) 1351-1355.

[39] A.J. Bard, L.R. Faulkner, Electrochemical Methods: Fundamentals and Applications, second., Wiley, New York, 2001.

[40] E.V. Suprun, F. Arduini, D. Moscone, G. Palleschi, V.V. Shumyantseva A.I. Archakov, Direct electrochemistry of heme proteins on electrodes modified with didodecyldimethyl ammonium bromide and carbon black, Electroanalysis 24 (2012) 1923-1931.

[41] D. Talarico, F. Arduini, A. Amine, I. Cacciotti, D. Moscone, G. Palleschi, Screenprinted electrode modified with carbon black and chitosan: a novel platform for acetylcholinesterase biosensor development, Anal. Bioanal. Chem. 408 (2016) 7299-7309.

[42] L. Blandón-Naranjo, J. Hoyos-Arbeláez, M.V. Vázquez, F. Della Pelle D. Compagnone, NADH oxidation onto different carbon-based sensors: effect of structure and surface-oxygenated groups, J. Sensors 2018 (2018).

[43] F. Arduini, F.D. Giorgio, A. Amine, F. Cataldo, D. Moscone, G. Palleschi, Electroanalytical characterization of carbon black nanomaterial paste electrode: development of highly sensitive tyrosinase biosensor for catechol detection, Anal. Lett. 43 (2010) 1688-1702.

[44] F. Arduini, C. Zanardi, S. Cinti, F. Terzi, D. Moscone, G. Palleschi, R. Seeber Effective electrochemical sensor based on screen-printed electrodes modified with a carbon black-Au nanoparticles composite, Sensor. Actuator. B Chem. 212 (2015) 536-543.

[45] F. Arduini, M. Forchielli, A. Amine, D. Neagu, I. Cacciotti, F. Nanni, D. Moscone, G. Palleschi, Screen-printed biosensor modified with carbon black nanoparticles for the determination of paraoxon based on the inhibition of butyrylcholinesterase, Microchim. Acta 182 (2015) 643-651.

[47] A. Wong, A.M. Santos, O. Fatibello-Filho, Simultaneous determination of paracetamol and levofloxacin using a glassy carbon electrode modified with carbon black, silver nanoparticles and PEDOT: PSS film, Sensor. Actuator. B Chem. 255 (2018) 2264-2273.

[48] P.B. Deroco, B.C. Lourencao, O. Fatibello-Filho, The use of modified electrode with carbon black as sensor to the electrochemical studies and voltammetric determination of pesticide mesotrione, Microchem. J. 133 (2017) 188-194.

49] S. Cinti, F. Arduini, G. Vellucci, I. Cacciotti, F. Nanni, D. Moscone, Carbon black assisted tailoring of Prussian Blue nanoparticles to tune sensitivity and detection limit towards $\mathrm{H}_{2} \mathrm{O}_{2}$ by using screen-printed electrode, Electrochem. Commun. 47 (2014) 63-66.

[50] S. Cinti, F. Santella, D. Moscone, F. Arduini, $\mathrm{Hg}^{2+}$ detection using a disposable and miniaturized screen-printed electrode modified with nanocomposite carbon black and gold nanoparticles, Environ. Sci. Pollut. Res. 23 (2016) 8192-8199.

[51] M. Portaccio, D. Di Tuoro, F. Arduini, F. Moscone, M. Cammarota, D.G. Mita, M. Lepore, Laccase biosensor based on screen-printed electrode modified with thionine-carbon black nanocomposite, for Bisphenol A detection, Electrochim. Acta 109 (2013) 340-347.

[52] N.B. Messaoud, A.A. Lahcen, C. Dridi, A. Amine, Ultrasound assisted magnetic imprinted polymer combined sensor based on carbon black and gold 
nanoparticles for selective and sensitive electrochemical detection of Bisphenol A, Sensor. Actuator. B Chem. 276 (2018) 304-312.

[53] S. Cinti, S. Politi, D. Moscone, G. Palleschi, F. Arduini, Stripping analysis of as (III) by means of screen-printed electrodes modified with gold nanoparticles and carbon black nanocomposite, Electroanalysis 26 (2014) 931-939.

[54] D. Talarico, F. Arduini, A. Amine, D. Moscone, G. Palleschi, Screen-printed electrode modified with carbon black nanoparticles for phosphate detection by measuring the electroactive phosphomolybdate complex, Talanta 141 (2015) 267-272.

[55] M.R. Tomei, F. Arduini, D. Neagu, D. Moscone, Carbon black-based disposable sensor for an on-site detection of free chlorine in swimming pool water, Talanta 189 (2018) 262-267.

[56] P.A. Raymundo-Pereira, A.M. Campos, F.C. Vicentini, B.C. Janegitz C.D. Mendonça, L.N. Furini, N.V. Boas, M.L. Calegaro, C.J. Constantino, S.A. Machado, O.N. Oliveira Jr., Sensitive detection of estriol hormone in creek water using a sensor platform based on carbon black and silver nanoparticles, Talanta 174 (2017) 652-659.

[57] P.B. Deroco, R.C. Rocha-Filho, O. Fatibello-Filho, A new and simple method for the simultaneous determination of amoxicillin and nimesulide using carbon black within a dihexadecylphosphate film as electrochemical sensor, Talanta 179 (2018) 115-123.

[58] G. Ibáñez-Redín, D. Wilson, D. Gonçalves, O.N. Oliveira Jr., Low-cost screenprinted electrodes based on electrochemically reduced graphene oxidecarbon black nanocomposites for dopamine, epinephrine and paracetamol detection, J. Colloid Interface Sci. 515 (2018) 101-108.

[59] M. Baccarin, F.A. Santos, F.C. Vicentini, V. Zucolotto, B.C. Janegitz, O. FatibelloFilho, Electrochemical sensor based on reduced graphene oxide/carbon black chitosan composite for the simultaneous determination of dopamine and paracetamol concentrations in urine samples, J. Electroanal. Chem. 799 (2017)
436-443.

[60] A. Wong, A.M. Santos, T.A. Silva, O. Fatibello-Filho, Simultaneous determination of isoproterenol, acetaminophen, folic acid, propranolol and caffeine using a sensor platform based on carbon black, graphene oxide, copper nanoparticles and PEDOT: PSS, Talanta 183 (2018) 329-338.

[61] G. Ibáñez-Redín, T.A. Silva, F.C. Vicentini, O. Fatibello-Filho, Effect of carbon black functionalization on the analytical performance of a tyrosinase biosensor based on glassy carbon electrode modified with dihexadecylphosphate film, Enzym. Microb. Technol. 116 (2018) 41-47.

[62] A.A. Lahcen, S.A. Errayess, A. Amine, Voltammetric determination of sulfonamides using paste electrodes based on various carbon nanomaterials, Microchim. Acta 183 (2016) 2169-2176.

[63] S.I.R. Malha, A.A. Lahcen, F. Arduini, A. Ourari, A. Amine, Electrochemical characterization of carbon solid like paste electrode assembled using different carbon nanoparticles, Electroanalysis 28 (2016) 1044-1051.

[64] M.M. Lounasvuori, D. Kelly, J.S. Foord, Carbon black as low-cost alternative for electrochemical sensing of phenolic compounds, Carbon 129 (2018) 252-257.

[65] J.H. Lee, J.Y. Park, K. Min, H.J. Cha, S.S. Choi, Y.J. Yoo, A novel organophosphorus hydrolase-based biosensor using mesoporous carbons and carbon black for the detection of organophosphate nerve agents, Biosens. Bioelectron. 25 (2010) 1566-1570.

[66] L. Xu, F. Guo, Y. You, J. Hu, Y. Miao, Z. Wu, L. Wang, Simple electrochemical sensor based on carbon-black paste electrode coupled with derivative square wave voltammetry for the determination of sulfites in rice wine, Int. J. Electrochem. Sci 11 (2016) 4586-4597.

[67] A. García-Miranda Ferrari, C. Foster, P. Kelly, D. Brownson, C. Banks, Determination of the electrochemical area of screen-printed electrochemical sensing platforms, Biosensors 8 (2018) 53-63. 